\title{
Construction of a velocity model of the brazilian pre salt based on Búzios Field - Preliminary results
}

\author{
Ammir Ayman Karsou ${ }^{1}$, Lucas Lima Navarro de Andrade ${ }^{1}$, Diego de Castro Rodrigues ${ }^{1}$, Ruann Carlos Mendanha da Silva ${ }^{1}$, \\ Lara Moreira Gadioli $^{1}$, Felipe Timóteo da Costa ${ }^{1}$, Marco Antônio Cetale Santos ${ }^{1}$, Wagner Moreira Lupinacci ${ }^{1}$, Djalma Manoel \\ Soares Filho ${ }^{2}$. \\ GISIS/UFF'. Petrobras².
}

Copyright 2019, SBGf - Sociedade Brasileira de Geofísica.

This paper was prepared for presentation at the $16^{\text {th }}$ International Congress of the Brazilian Geophysical Society, held in Rio de Janeiro, Brazil, August 19-22, 2019.

Contents of this paper were reviewed by the Technical Committee of the $16^{\text {th }}$ International Congress of The Brazilian Geophysical Society and do not necessarily represent any position of the SBGf, its officers or members. Electronic reproduction or storage of any part of this paper for commercial purposes without the written consent of The Brazilian Geophysical Society is prohibited.

\section{Abstract}

Migration techniques based on ray tracing, such as Kirchhoff, has been widely used in the seismic processing industry, but the current Brazilian moment requires migration based os wave equation, as RTM, which is capable of imaging features where the ascending ray tracing cannot. Creating a Brazilian model, representative, and still useful for academy and industry is a challenge that we have decided to follow. This work has as main objective the description of the building of a velocity model at the Búzios Field, in the Santos Basin, to have a complex, plausible and realestate-based model of properties. For this, KPSDM seismic data (granted by ANP) were used integrated to well data in the geological interpretation. The resulting velocity model seems reliable in representing the most important features of the Búzios Field, which would help to understand how the migration and inversion algorithms respond in a geologically complex and heterogeneous model.

\section{Introduction}

With the increasing geologic complexity, the need to image the Earth's internal structures have arises dramatically. Therefore, seismic is still the most important method in a geophysical survey. With the introduction of digital records, it was possible to improve data processing and the production of increasingly reliable models (REDDY, 2019). The response recorded on the various types of receivers (hydrophones, geophones, nodes) can be described as a function of propagation velocity and subsurface transmission and reflection paths that reveal a rich information of subsurface geology (KEAREY, 2002).

Seismic has been largely responsible for lead hydrocarbon exploration around the world and being fundamental in increasing, recognizing and proving oil reserves.

Seismic acquisition has been following closely the technological and computational advances, because it is an industry that needs large capacity for data storage and processing. It went from the analog to the digital along the digital revolution of the 60's. The number of channels and cables was increased, which provided a greater range of coverage. A few years later, in the 1980s, seismic began to show images in 3 dimensions, and this in a way, also boosted the computational industry. Many algorithms for seismic data processing were developed before there were machines robust enough to calculate them (YILMAZ, 2001).

With the advances of exhaustive years of research and now with more capable computers, geophysicists were able to provide images not only in three dimensions, but representing lateral variations of velocity and providing an image in depth. This is only possible with a velocity model that approximately represents subsurface geology, a 3D acquisition large enough to model all possible paths that the waves have traveled to reach the receiver and huge capacity machines.

Having a model that represents the geological complexity is extremely important to support the new techniques. Knowing fully the structure of the model we are able to verify if the algorithms is adequate for the expected imaging. A famous model used to for testing algorithms is the Marmousi model. Marmousi was designed based on a real situation (Cuanza Basin) and to have a complex structure, which means that it should contain many reflectors, steep falls and strong velocity gradients in the vertical and lateral directions (VERSTEEG, 1994). Although the Marmousi model has been widely used in the academy to test new techniques for more than 25 years, during the exploration of the pre salt new challenges have arised.

The halokinesis present in brazilian basins are far more complex than it was presented at that time. In this context, the aim of this work is to construct a more geologically realistic velocity model for the Santos Basin, including faults, the thick package of salt and to represent its peculiar geometry. Our model comes precisely to help both academy and industry in this regard. We have developed a complex model that will require migrations that perhaps based on ray tracing will not be able to solve. In addition to representing challenges to the Full Waveform Inversion (FWI) technique, because it contains important layers with high contrast of velocity but with small thickness, which turn difficult for the inversion in the frequency range that the FWI has been applied in the industry. 


\section{Velocity model building performed in the industry}

Nowadays, the industry has faced imaging problems related to the salt body either because of the stratification within the salt or by encapsulated sediments within. These latter cases are known to have not been solved with Kirchhoff migration algorithms, which has pushed the industry to solutions that do not go through ray tracing, as an example of RTM and Least Square Migration (ZENG et al., 2016). But even these newer, complex and expensive techniques are still being confronted with new problems every day, such as thin layers of anhydrite on top of salt, multiple interbedded layers that hinder the imaging of the reservoir such as sylvite, carnallite and tachydrite (FERNANDES et al., 2017). Time migration does not correctly honour Snell's law, leading to lateral mispositioning of energy, especially in caotic regions such with presence of salt. A consequence of this approximation is that on a length scale similar to the depth of the reflector, time migration assumes the velocity to be laterally invariant. A more effective tool is using 3-D prestack depth migration, which allows imaging of reflectors under the salt layers and of irregular bodies. Ray-tracing modeling can simulate seismic illumination problems to allow better interpretation of subsalt region (MUERDTER et al., 2001).

Kirchhoff and beam techniques handle lateral velocity variation very well and have a good dip response as well, as long as the spatial wavelength of these changes is much longer than the seismic wavelength. However, for lateral velocity variation on a length scale similar to the seismic wavelength, ray techniques are no longer appropriate (JONES, 2010).

Migration techniques have evolved a lot in recent years, no longer working only with ray tracing, but also with methods based on the wave equation. However, regardless of the technique, without a good velocity model both will not be able to put the events in their correct locations, or even in the methods of the wave equation, like RTM, there will not be the correct imaging, often causing reflectors are not imaged.

In search of a better velocity model, interdisciplinary teams has been formed with the aim of allying seismic interpretation with processing, providing models capable of correctly migrating data, deciding which technique is more efficient to image the target and quickly solving the velocity model problems based on quality controls made with the migrated data, combining tomography, FWI and geophysical and geological expertise.

There are model building schemes that work from the topdown (layer stripping). The first one to be modeled is the water layer (for marine data). Once the model is filled with water velocity (water flood), the model will be able to migrate the data correctly only from the top to the horizon of the sea floor. The interpretation team will track this horizon, and once validated, the model should be modified only from this horizon down.

To buid a velocity model in Santos basin, especially if the pre salt is the goal, modeling well the salt represents an extremely important part in the model building. Using the Layer cake (JONES, 2010) technique, after the waterflood and seabed picking stage, the sedimental flood stage begins, aiming at correctly positioning the top of the salt.
In order to do so, from the bottom of the sea down is completely filled with the average sediment velocity of the basin. Tomography and inversion techniques are used in this step to ensure the accuracy of the top layer of the salt (the last event modeled in this step). Once the top of the salt is interpreted, the stage of the saltflood begins where, from the top of the salt down will fill the model with medium velocity of salt. What is expected is that after this step is able to perfectly visualize the salt base, the last important stage to be interpreted. In any event with considerable velocity contrast, not be modeled, will cause imaging problems at the base. Some examples are overhangs, stratified salt filled within sediment velocity, vulcanics, or even mistakes during the interpretations, normally caused by some high velocity layer just above the top of salt.

Building a velocity model requires attention, advanced inversion techniques, a multidisciplinary team and the use of all available tools, such as well logs information within the acquisition or non-seismic data and production data.

\section{Geological context}

Búzios Field is located in the central portion of the Santos Basin, approximately $180 \mathrm{~km}$ from the coast of Rio de Janeiro, and with a mean $1900 \mathrm{~m}$ deep. Figure 1 shows the location of the Búzios Field.

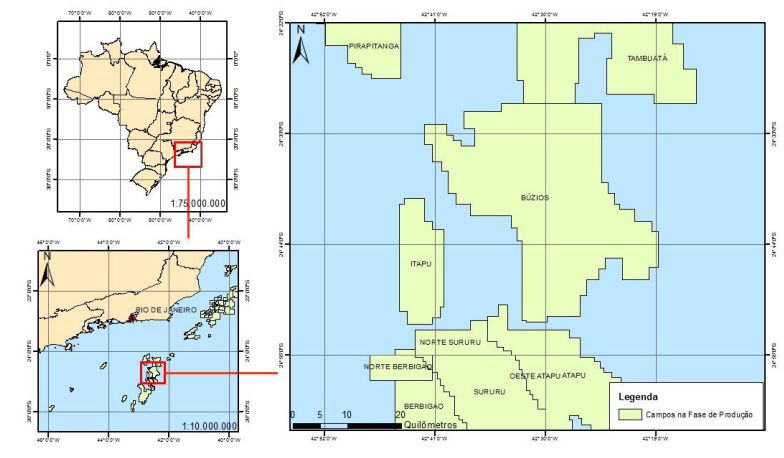

Figure 1: Location of Búzios Field (ANP, 2016)

Santos Basin corresponds to a passive margin basin generated during the Neocomian, related to the rupture of the Gondwana and the opening of the Atlantic Ocean. The thickness of the sedimentar section can reach up to $15 \mathrm{~km}$ (MIO et al., 2005). Figure 2 shows the stratigraphic chart, illustrating each Formation time and mean thickness in the Santos Basin.

The sedimentary column of the basin is composed by three main supersequences, being rift, post rift and drift. The rift supersequence is comprehended from Hauterivian (Rio da Serra and Aratu) to the Aptian (Jiquiá), envolving the sediments coming from the Gondwana opening and is represented by the Camboriú Formation. Formation Piçarras and Formation Itapema, are composing the old formation and now named Guaratiba Group. Between the Aptian and the begining of the Albian marked by the discordance of the local stage Alagoas, the post rift supersequence is characterized by a continental transitional environment to a shallow marine deposits constituted by the Barra Velha and Ariri Formations, these also belong to the Guaratiba Group. From a probable thermal subsidence reflected in the coastal 


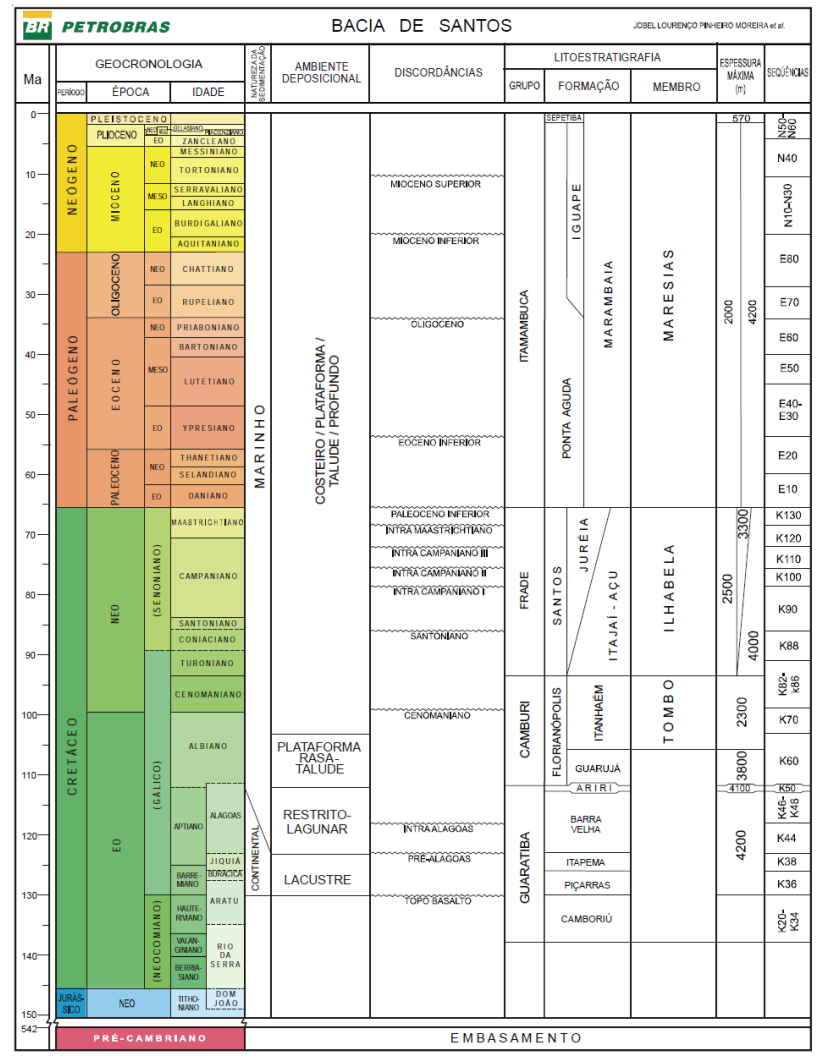

Figure 2: Stratigrafic chart of Santos Basin (MOREIRA et al., 2007)

marine sedimentation, evolving to a platform followed by a deep sea. The drift supersequence is extended from the Albian to the Pleistocene, attributed to (MOREIRA et al., 2007).

The geology in the Búzios Field englobes a big parte of the units described in the basin. In this work, the highlighted units are the Formations Camboriú, Barra Velha and Ariri from the Guaratiba Group and the Marambaia Formation from the Itamambuca Group.

Itapema Formation is composed by sediments deposited from the Neobarremian to the Eoaptian, having its bottom limit the inner barremian unconformity that separates the Buracica and Jiquiá stages. The upper limit is marked by the Pré-Alagoas unconformity, characterized by black shales, being the some portions composed by shelly fragments frequently dolomitezed and/or silicified, and its top corresponds to the upper limit of the rift phase.

It was deposited during the Eoaptiano, Alagoas, inferior to the Barra Velha Formation, which is separated from the top of the Itapema Formation by the pre-Alagoas discordance. Its deposition is marked by microbial limestones, stromatolites, laminites and / or shales, as well as grainstones and packstones that may be partial or totally dolomitized. Records also indicate the occurrence of magmatic intrusions in the midst of formation.

The Ariri Formation, top of the Alagoas stage, corresponds to the evaporites that were deposited in the Neoaptian, composed mostly by halite and anhydrite, with global presence of tachydrite, carnallite and sylvite.

Due to the coverage and distribuition of the evaporitic section, from the Albian the tectonic arrangement is modified in response to the salt mobility, having as consequence the formation of big halokinetic structures as diapirs and walls of kilometric thicknesses in the deeper portions of the basin (MILANI et al., 2001).

Lastly, Marambaia Formation has its deposition from the Paleocene till today, showing thick sections of shale and marl, with intercalations of turbiditic sandstones.

\section{Creation of the velocity model}

For the creation of the velocity model, were used a 3D seismic survey with a geometry of $12,5 \times 25$ meters, migrated in depth using Kirchhoff migration and four wells containing the sonic and density logs. The methodology used in this work for the velocity model building are enumerated in five steps as shown below:

\section{Loading of the seismic and well data.}

2. Delimitation of target formations.

3. Interpretation of the seismic horizons.

4. Interpolation of interpreted horizons.

5. Extrapolation of the sonic well data along the seismic horizon.

The step (1) is the loading of the data used, which show some problems in the data. The seismic survey has a discontinuity in its middle section, this is due to a corruption in the SEG-Y file. The well logs are not performed along its total depth, that happens because two logs are performed only on the reservoir zone, which is around $5400-5900$ $\mathrm{m}$. Step (2) delimits the zones of interest in the seismic section. As the extrapolation method respect the geometry of the seismic horizons, these horizons must be chosen appropriately to represent as close as possible the geology in the Búzios Field. Therefore, three post salt horizons were chosen: one being the water bottom and two being strong reflectors due erosive events inside the Marambaia Formation that are shaped by the faults in the model. Then, were selected the salt top, salt bottom and the economic basement. The interpretation of the seismic cube is the step (3). As the velocity model builder does not account faults in its creation, therefore, the horizon was picked along the fault line so it can simulate the fault line in the velocity model. Almost all horizons were well defined, with the exception of the economic basement, which was mapped with TecVa attribute (BULHÕES and AMORIM, 2005). In step (4), all seismic horizons are interpolated using the convergent interpolation method. Lastly, the extrapolation of the data is done by matching depth of the horizon with the well sonic log in the same depth, and then this velocity value is extrapolated along its geometry. After all this steps, the well log heterogeneity is distributed with the geometry reference of the top horizon, generating the final property model presented in this work.

\section{Results and Discussion}

Figure 3 shows the seismic section selected to show the seismic section selected to show these successions 


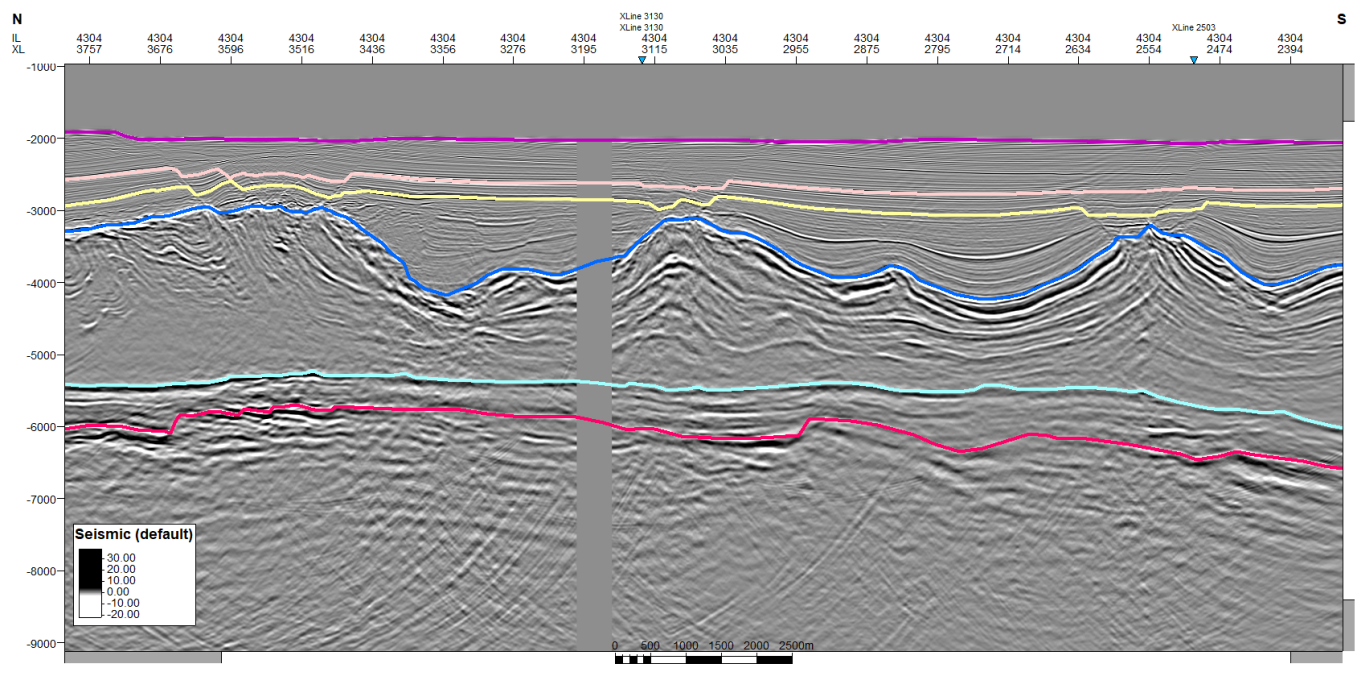

Figure 3: The seismic line chosen to represent the Búzios Field with the horizon interpretations.

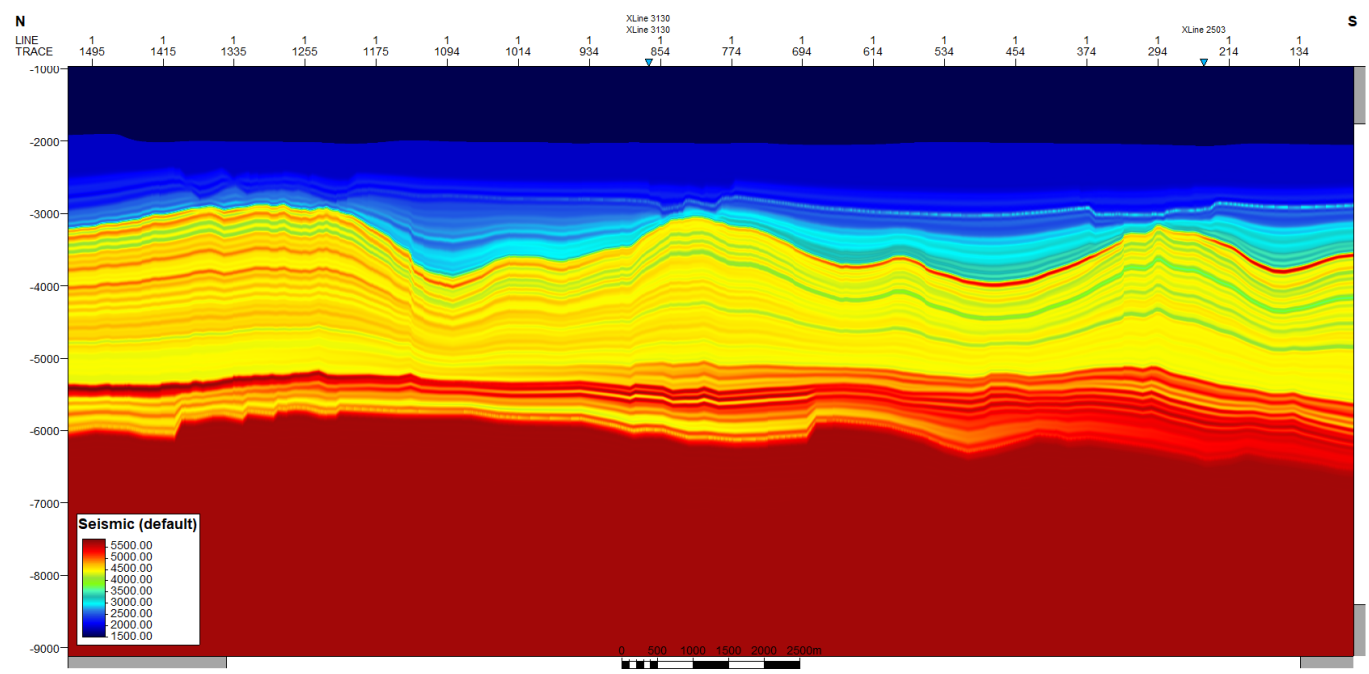

Figure 4: Resulting velocity model generated from the steps of interpretation and well extrapolation.

these successions and the interpreted horizons selected to create the velocity model.

The horizons selected were the Marambaia Formation in purple (water bottom), two strong reflectors represented in pink and yellow to simulate the faults generated by the salt dome, in blue is the Ariri Formation (top of salt), Barra Velha Formation (base of salt) in green and the Camboriú Formation in red, which is a sequence of igneous rocks chosen as the economic basement of the model.

Figure 4 present the final velocity model for the Búzios Field. The geological history presented in the model consists of four main structures from bottom to top:

1. The first corresponds to economic basement where the top is a continuous igneous rocks of the Camboriú Formation. This region is considered with a homogeneous velocity of $5500 \mathrm{~m} / \mathrm{s}$.

2. The second region is constituted of carbonate reservoirs, with a range of velocity varying from 5000 to $5500 \mathrm{~m} / \mathrm{s}$.

3. The third region is the salt area. Our model takes into account the stratified nature of the salt as it happens quite often in Santos Basin. One interesting feature is the low velocity layers inside the salt due to the tachydrite presence.

4. Lastly, the post salt region, which faults are well represented in the model.

The velocity model generated seems reliable, once all structures present in the Búzios Field are well represented in the model. The most important features are the reservoir 
geometry, the salt heterogeneity and the post salt deformed rocks. The model can be used a conceptual velocity model to describe the geology of the field, possibly being used for migration and inversion algorithms. Some adjustments will be done to improve, such as the velocities mistakes inside the salt. These velocities were extrapolated directly from the well logs.

As not all features in Santos Basin are contemplated in Búzios Field, we seek to insert typical and challenging issues in this model such as:

1. Cap rock formation in salt bodies with high velocities as anhydrite, which is often oversimplified, especially if the cap material is thin or confused with flank sediments and can distort the final image because of using inappropriate velocities in the vicinity of the salt.

2. Typical Overhangs of complex geometries associated with seismic arrivals with complex travel paths, oneway versus two-way propagation imaging issues and refraction-related events which often making it extremely difficult to make sense of the data we are working with.

3. Encapsulated sediments in the salt body with difficult identification that, when not included in the velocity model, compromise the resolution at the base of the salt and in the pre salt.

And alongside these changes, it is intended to build a second velocity model using the layer cake imaging technique, using the tomography, FWI and others, aiming to create a velocity model that is not so geological but is more useful to image solutions on the real data.

\section{Acknowledgments}

We'd like to thank: ANP (Agência Nacional do Petróleo, Gás Natural e Biocombustíveis) for providing the data of Campo de Búzios; to GISIS Lab, for providing the necessary tools to perform this work; to CAPES (Coordenação de Aperfeiçoamento de Pessoal de Nível Superior) and FEC (Fundação Euclides da Cunha) for providing scholarship for our students; to CGG for providing an academic license of Geoview; to Schlumberger for providing an academic license of Petrel; and to Professor Marco Antonio Cetale for the support and guidance.

\section{References}

ANP. Plano de desenvolvimento aprovado reunião de diretoria $n^{0} 832$ de 18/02/2016 - resolução $n^{\circ}$ 093/2016:, 2016.

BULHÕES, . M., and AMORIM, W. N., 2005, Princípio da sismocamada elementar e sua aplicação à técnica volume de amplitudes (tecva): 9th International Congress of the Brazilian Geophysical Society.

FERNANDES, L. F., MAUL, A. R., and CETALE, M. A., 8 2017, O sal estratificado e sua importância na modelagem de velocidades para fins de migração sísmica: Master's thesis, Universidade Federal Fluminense.

JONES, I. F., 2010, An introduction to: Velocity model building:, volume 1 EAGE, UK.
KEAREY, P., 2002, An introduction to geophysical exploration:, volume 86 Blackwell Science Ltd, a Blackwell Publishing Company, UK.

MILANI, E. J., BRANDÃO, J. A. S., ZALÁN, P. V. Q., and GAMBOA, L. A. P., 2001, Petróleo na margem continental brasileira: Revista Brasileira de Geofísica.

MIO, E., CHANG, H. K., and CORRÊA, F. S., 2005, Integração de métodos geofísicos na modelagem crustal da bacia de santos:, volume 23 Revista Brasileira de Geofísica, BR.

MOREIRA, J. L. P., MADEIRA, C. V., GIL, J. A., and MACHADO, M. A. P., 2007, Bacia de santos:, volume 15 Boletim de Geociências da Petrobras, Rio de janeiro, BR.

MUERDTER, D., KELLY, M., and RATCLIFF, D., 7 2001, Understanding subsalt illumination through ray-trace modeling, part 2: Dipping salt bodies, salt peaks, and nonreciprocity of subsalt amplitude response: The Leading Edge, pages 688-697.

REDDY, P., 03 2019, Historical development of seismic imaging technique - an overview:

VERSTEEG, R., 1994, The marmousi experience: Velocity model determination on a synthetic complex data set:.

YILMAZ, Ö., 2001, Seismic Data Analysis:, volume 1 SEG, Tulsa, OK, USA, 2 edition.

ZENG, C., DONG, C., and WANG, B., 3 2016, Adaptive least squares rtm with application to subsalt imaging: The Leading Edge, pages 253-257. 